\title{
Thinking on the Future Development of Chinese Modern Art Design
}

\author{
Chuangye Ma \\ School of Engineering \\ Huanghe Science and Technology College \\ Zhengzhou, China \\ e-mail: 24906893@qq.com
}

\begin{abstract}
The designers link their abstract ideas in the brain with real objects, and then show them with the most visual way, which we usually call art design. Whether it is environmental art design, industrial art design, fashion art design or others, designers see the nature of things through the phenomena, seize its core essence, finding their own unique insights, and extend out some thinking and ideas. Only by seizing the essence can art design be developed. Since the reform and opening up, China's art design industry has sprang up and made very big achievements, however, challenges and problems still exist today. As the international cooperation and division of labor is getting closer and closer, the ecological problems are becoming more serious. People are beginning to pay more attention to the future development trends of modern art designs. This paper mainly elaborates the future prospects of modern art design and discusses the development methods of modern art in order to share with colleagues.
\end{abstract}

Keywords-modern art design; sustainable development; green design; human-oriented innovation; industrialization

\section{INTRODUCTION}

Everything has its own value. Whether that is practical value or aesthetic value, it can be realized through creation because it extends the value idea of objects. It is a kind of sustainable development. Art design, existing as a thing, should follow the design concept of sustainable development in the design process in order to create value, and the labor crystallization or labor tool obtained is known as the concept of "artifacts". This concept is about human survival instinct. The objects created to meet human's demands have innate value for being. Artistic creations, as objects for the beautification of human life, have an important role in enriching human spiritual civilization and improving human aesthetic values. We cannot see this kind of value, but it does exist. These kind of artistic objects are products of human spiritual civilization development and also artistic media in order to sublimate human life. The media is necessary to exist in the development process. Designers should first figure out social needs, in other words, the direction of social development, before creating any design, for there exists a development trend of exploration, utilization and reasonable recycling in human society. The design works may also not be out of this trend. Most of the designers make art design without departing from the "artifact" concept, or else it will deviate from the rules of human existence. The design works, not conforming to the rule of sustainable development, will not be accepted by society. In general, art design should conform to the rule of sustainable development, which is an extending trend in the development of the international economic globalization and regional economic collectivizing. If one design may cause a shortage of resources, loss of species, death of mankind or incur other human survival problems, it will not be allowed to continue to exist, because it is against the trend of the development of human society. Therefore, it is required to explore the development direction of human spiritual civilization to develop the modern art design, on this basis also to check whether the spiritual value and aesthetic value will damage the hard target for the sustainable development of human society. The combination of the two is the future direction and goal of modern art design.

Since the founding of New China, we have made great development on politics, economy, technology, culture etc. Especially with the implementation and deepening of reform and opening, art design majors have developed at an unprecedented pace. In recent years, colleges and universities have expanded enrollment, so the Art Design Major is already overly saturated. In addition, with the aggravation of the ecological environment pollution, people have to reposition the development of art design, making it possible to improve environment and use resources efficiently, hoping to contribute to all of humankind.

\section{DEMAND: THE INSTINCT OF DESIGN}

As times pass by, human economic civilization is constantly developing. People have a big change in appreciation of and requirements for art works. The change of aesthetic values and spiritual civilization concepts also brings designers new challenges. Many old art designs with time significance were deeply affected by deep tradition concepts, so it is too difficult for such designers to face new development situations and challenges. The culture, background and historical significances are different in transition from the old times. It could destroy its original charm by adopting new design thinking models, accidentally resulting in ruining the artwork. However, this 
new design pattern changed the previous outdated design form to meet the demands of the development of society, which put art design to another development highest point. Art design will develop rationally. It is a development model to make humans more comfortable and cozy. With continuous improvement of our value orientation and spiritual needs, designers have to innovate and design works that meet human needs in order to catch up with this mode of thinking. Any design works first have to meet basic needs and then other requirements. The artificiality we created is to facilitate our life. The design, at the beginning, simply was to meet certain life demand or clear away some obstacles. Once these demands were satisfied, it would develop towards artistic direction. For example, a match is for the use of lighting a fire. With the continuous development of human society, the match became backward and outdated. Designers created the lighter to replace the match as a new tool to make fire. It is a design for the development of society, as well as a reform and innovation, but this design still does not break away from the need level. When the lighter is becoming increasingly popular, people begin to design lighters with decorative value. At this time, it is truly through innovation and development of art design that the design principle is improved to a higher level. We can describe the development history of the lighter with four words "survival of the fittest". When the design product is not accepted by humans or gradually eliminated by the pace of the times, then this art design goes on the edge of decline, or the starting point of innovation. Through continuous pursuit of satisfying people's needs, the new works make people and things become unified in this era, so as to lead the trend of the times and achieve the aesthetic value that humans want.

\section{NATIONAl CHARACTER: THE SOUl OF DESIGN}

As a great country with five thousand years of traditional culture, the Chinese nation has a long cultural heritage. This heritage has become the stamina for China to walk to the world. These profound Chinese heritages come from many Chinese ethnic groups. These ethnic groups, with different culture and backgrounds, have propped up the bracket of Chinese culture, which is also a bridge of communication with the world. When art design is integrated with the connotation of the national culture, it will become more likely to be accepted by humans and it will be easier to withstand the erosion and baptism of time. Only by integrating the national culture into art design products, can they be promoted to the world without hindrance. At the same time, they can be understood and accepted by this world. This is the result and development trend of frequent economic and cultural exchanges among countries in the world. The sustainable development of art design became inseparable with its national character. Designers design works according to multi-ethnic styles and artistic characteristic, and consider national things from multiple angles. In this way, designers greatly improve human artistic tastes and aesthetic values. In designing art, designers should not forget the fact that they are a representative of our country. Therefore, it has become a responsibility of designers to carry forward the national culture and tradition and promote the art works with distinctive national colors to the world.

\section{INNOVATION: THE NUTRITION OF DESIGN}

We need innovation in art design, because some art works may be abandoned by the times or due to these reasons some art works are no longer needed by people. However, this kind of innovation does not mean total dismissal. We cannot completely ignore the historical significance behind art works, but consider the tradition in innovation, because it is the development direction of true art. Some national things are integrated into art design, and the cultural connotation in these things will not disappear with the passage of time. They are not outmoded or outdated, and will always keep up with the pace of human progress. However, to be blindly conservative or only focusing on one thing, it is also bound to be eliminated by the times. Therefore, it is an innovative and specific approach for the development of art design by adding new thinking modes to create a new art design concept. Many designers may give their design work a strong national color. The advantage of this is that it can carry forward the national culture, and these design works are more likely to be accepted by people. However, the blind pursuit of the nation character will make design work single, unattractive, and even some designers are very receptive to foreign cultures. The idea is actually not very conducive to the development of art design. We should remain calm in the face of an exotic product, and avoid blind rejection or acceptance. We should selectively absorb foreign culture to expand our own connotation, nourish the soul of the work and deepen its meaning. How to treat tradition and innovation in art design properly? How to treat the influence of non-native cultures on art design? They are topics to be studied in the future. It needs constant practice and hard work of countless artists to determine the development direction of artistic creation. Only by continuous excavation and exploration can we find the true development trend and the essence of art design.

\section{GREen Design: THE REQUiREMENT OF THE TIMES}

In the 21 st century, a growing population, resources and ecological environmental problems have brought humanity to face huge challenges of survival. In such a situation, the green design is put on the agenda. For designers, it is necessary to take ecological benefits and rational use of resources into account. Designers should try their best to achieve the goal of environment and resource protection and resource waste reduction as far as possible in designing works, so that their design behaviors both realize the social value of people and create the value of nature protection, enabling the harmonious coexistence of all things in the world. In green design, $3 \mathrm{R}$ is the core principle, which means to reuse, reduce and recycle raw materials. It can reduce material and energy consumption and reduce the discharge of harmful substances, and help sort recycled products and parts, and then reuse them. Green design should focus on changes in technology and ideas. We can fully implement green design through new ways. Currently, the green design concept has been widely applied to many 
fields. Take roof greening as an example. In terms of extensive meaning, roof greening refers to tree planting on the roof of buildings, walls, overpasses and structures, rooftop or artificial rockery. The roof greening increases green areas in the city, reduces the urban heat island effect, improves environmental appearance, the quality of our daily life and work environment, weaken the noise in the city and protect the roofs of buildings to extend the roof life. What is more, roof greening can reduce indoor temperature on the top floor and effectively improve air humidity and purification of the air. Since the Great Wall Hotel first created and built a roof garden in 1983, various cities in China are trying to use new technology to afforesting roofs. In this way, the ecological environment is improved and the view and hearts of people are beautified and purified.

\section{USER-FRIENDLY DESIGN: THE REFECTION OF FUTURE}

People-oriented design is the main feature of userfriendly design. In user-friendly design, users are the core of the design. At present, most design activities are carried out usually from our own demands, mainly including material demand and spiritual demand. The former mainly covers food, clothing, housing, daily necessities, travel etc. The latter mainly covers arts, theater, sense of duty, literature etc. The design works of designers shall not only meet people's material demands, but more importantly shall meet their spiritual demands, which requires designers to study ergonomics completely and scientifically. The ergonomics requires design works to be consistent with the social environment and needs in all aspects, especially in line with people's mental and physical characteristics and other ergonomics requirements. Of course, the user-friendly design philosophy is developing constantly, but its connotation and meaning are not invariable. In future development, the design will develop toward the direction of the cultural exchanges, and gradually get rid of the shackles of the material, and express the needs of humanity. Based on this, designers should apply development perspectives to treat the user-friendly design concept, rather than rest on its laurels, otherwise the design will unable to keep pace with the times and thus be eliminated gradually.

\section{THE INDUSTRIAL DEVELOPMENT: THE FUNDAMENTAL OF ART DESIGN}

As the international cooperation and division of labor is becoming closer and closer, many countries have begun to stress the industrialization in the development of art design, and have made a success. For art design, innovation is a very important factor. Only by constant innovation, can we be able to stand in a leading edge in this increasingly fierce competitive society. In the world, innovation has become the soul of design. For example, the Japanese animation industry is always in a leading position in the world. They have advanced technology and develop unique creations, which cater to the tastes of all consumers at all age stages, so that they have a large consumption market. Their animation design has got rid of the limit of age. In addition, the Japanese government clearly put forward the industrialized operation mode in the development of animation, meanwhile they stress to export their animation products to different countries, showing Japanese culture to these countries and carrying forward their national cultural connotation, thereby enabling the improvement of Japan's international influence. Our country is a big manufacturing country. Our manufacturing products occupy the international market. Many products are noted the words "Made in China". However, China only manufactures products and provides raw materials and cheap labor, etc. The Europeans and Americans grasp the real beneficial links, such as product design and market return etc. We put a lot of manpower and raw materials in, but only get a poor return. Under the situation of increasingly closer international division of labor, the international competition has not only existed in companies and products, but entered into the new industrial chains. Based on this, our future design development trend is that: we will transform from the big manufacturing country gradually into a great creative country, establish our own brand with national characteristics in the world and attach importance to reputation; our enterprises will take creative design at its core to walk towards manufacturing and sales globalization.

\section{CONCLUSION}

Compared with European and American developed countries, art design in China started late, resulting in our design concepts being relatively backward. Nevertheless, we can see the development prospect of our design industry. With adequate labor force, large population consumption volume, a lot of raw material places of origin and five thousand years of cultural heritage, we may lay a good foundation for the art design industry. The 21 st century represents one hundred years of development within the art design industry. We believe that our design industry will move towards a brilliant future with Chinese people's efforts, unity, hard work and innovation.

\section{REFERENCES}

[1] Xu Jin. "Livelihood" Philosophy in Design - Thinking of the Development of Modern Art Design Education. Journal of Big Stage, 2012 (11).

[2] Zhang Na, Zhu Chengshi and Qu Yehua. Discussion on the Development Trend of Chinese Modern Art Design. Journal of Youth Writers, 2010 (18).

[3] Zhang Ling. To See Future Art Design from the Development of History. Journal of Literary Contend, 2011 (06). 